\title{
ESPECTROSCOPIA MÖSSBAUER NA CARACTERIZAÇÃO DE COMPOSTOS FERROSOS EM SOLOS E SUA RELAÇÃO COM RETENÇÃO DE FÓSFORO
}

\author{
Nilton Curi \\ Depto. de Ciência do solo, Universidade Federal de Lavras, 37200-000 Lavras - MG, Brasil \\ Paulo Emilio Ferreira da Motta \\ Embrapa Solos, 22460-000 Rio de Janeiro - RJ, Brasil \\ José Domingos Fabris \\ Depto. de Química, Universidade Federal de Minas Gerais, 31270-901 Belo Horizonte - MG, Brasil \\ Luiz Carlos Alves de Oliveira* \\ Depto. de Química, Universidade Federal de Lavras, CP 3037, 37200-000, Lavras - MG, Brasil
}

Recebido em 15/10/07; aceito em 29/2/08; publicado na web em 28/7/08

\begin{abstract}
MÖSSBAUER SPECTROSCOPY IN THE CHARACTERIZATION OF FERROUS COMPOUNDS IN SOILS AND ITS RELATIONSHIP WITH PHOSPHORUS RETENTION. The chemical role of iron-bearing compounds on the dynamics of phosphorus in selected Brazilian latosols was investigated. The iron oxides were characterized in an attempt to assess their main chemical-mineralogical properties influencing the ion sorption mechanisms in those pedosystems. It was found that increasing total iron contents tend to increase the phosphorus adsorption capacity in the selected soils. $110 \mathrm{~K}$-Mössbauer data reveal that the dominant iron oxides are hematite and goethite. Particularly for the yellower soil samples some prominent doublets, more certainly due to superparamagnetic relaxation, may be assigned to corresponding fractions of relatively small-sized particles.
\end{abstract}

Keywords: iron oxides; phosphorus sorption; Mössbauer spectroscopy.

\section{INTRODUÇÃO}

A essencialidade do fósforo para o desenvolvimento das plantas decorre de sua função na constituição das membranas celulares, na estrutura molecular de fosfolipídeos, de ácidos nucléicos e de compostos que armazenam e fornecem energia metabólica, via ATP (tri-fosfato de adenosina). O fósforo é, pois, elemento químico indispensável em muitos processos metabólicos vitais dos vegetais, como na fotossíntese, na síntese de macromoléculas, incluindo carboidratos, proteínas e gorduras, e na absorção ativa de nutrientes do meio. ${ }^{1}$

Em solos ácidos, também mais ricos em óxidos de ferro, como é o caso dos Latossolos, pode ocorrer, e com alguma freqüência ocorre, fixação de fósforo, tornando-o, em escala variável, indisponível para a bio-absorção. O aproveitamento dos Latossolos para a atividade agrícola, quase invariavelmente, requer adubação, visando a adequação da fertilidade à necessidade da cultura, o que altera a distribuição de fósforo, em diferentes formas químicas, no solo. A quantidade do nutriente a ser aplicada para o suprimento adequado das necessidades da cultura deve considerar, portanto, a capacidade de retenção pela fase sólida mineral, que condiciona a indisponibilidade química e limita o aproveitamento nutricional pelos vegetais. Mesmo considerando a fração residual que pode permanecer disponível, depois de completada a retenção na superfície sólida, a recuperação biológica do fósforo é, de modo geral, incompleta, dificilmente ultrapassando $50 \%$ do fósforo adicionado na forma de fertilizantes, especialmente em Latossolos. Nas condições de maiores proporções de minerais de óxidos de ferro, a fixação de fosfato é notadamente maior e o fósforo tende a ocorrer em formas menos lábeis, comparativamente àqueles solos com mineralogia mais caulinítica ou gibsítica. ${ }^{1-3}$

\footnotetext{
*e-mail: luizoliveira@ufla.br
}

O presente trabalho teve como objetivos: caracterizar, especialmente por espectroscopia Mössbauer na temperatura do ambiente ( $298 \mathrm{~K})$ e a $110 \mathrm{~K}$, as espécies químicas ferruginosas ocorrentes em Latossolos brasileiros representativos e relacioná-los com a capacidade de adsorção de fósforo, para os pedossistemas selecionados.

\section{PARTE EXPERIMENTAL}

\section{Solos utilizados}

Para o estudo, foram utilizados cinco Latossolos brasileiros, argilosos e muito argilosos, abrangendo ampla faixa de variação nas proporções de hematita e goethita. De cada perfil de solo selecionado, coletaramse amostras em duas condições de campo: sob vegetação nativa e em áreas adjacentes às anteriores, sujeitas ao manejo de cultivo agrícola por longo tempo, em sistemas de produção envolvendo calagens e adubações fosfatadas periódicas. Com o procedimento experimental adotado neste trabalho procurou-se dispor de pares de solos com atributos físicos e mineralógicos comparáveis, mas com conhecidamente diferentes capacidades de adsorção de fósforo, como resultado do manejo agrícola prolongado. A simbologia "NC" equivale, aqui, a "Não Cultivado" para as amostras de solo sob vegetação nativa e "C" significa "Cultivado".

As classes dos solos selecionados foram: Latossolo Amarelo coeso (LAx), originado de sedimentos da Formação de Barreiras, Latossolo Amarelo distrófico (LAd), originado do produto de alteração de gnaisse granítico, Latossolo Vermelho ácrico (LVw), desenvolvido de sedimentos de cobertura terciária, Latossolo Vermelho distroférrico, derivado de gabro (LVdfg) e Latossolo Vermelho distroférrico, derivado de tufito (LVdft).

As frações argila das amostras de solo, obtidas pelo método da pipeta, ${ }^{1}$ foram submetidas ao tratamento com $\mathrm{NaOH} 5 \mathrm{~mol} \mathrm{~L}^{-1}$ fervente, ${ }^{2}$ para concentração dos óxidos de ferro (fração argila ferroconcentrada), como preparação para as análises mineralógicas. 
Caracterização mineralógica da fração argila ferroconcentrada dos solos

Os materiais de solo foram caracterizados por: difratometria de raios $\mathrm{X}$ (DRX), em difratômetro Philips, com variação angular de $20-80^{\circ}(2 \theta)$, radiação de $\operatorname{CoK} \alpha(\lambda=1,78897 \AA)$ e velocidade de varredura de $1^{\circ}(2 \theta)$ min $^{-1}$; espectroscopia Mössbauer, CMTE modelo MA250, com fonte de ${ }^{57} \mathrm{Co} / \mathrm{Rh}$ nas temperaturas de 110 e $298 \mathrm{~K}$.

O teor de alumínio na goethita foi determinado após a quarta extração do tratamento com ditionito-citrato-bicarbonato (DCB), a fim de certificar-se da remoção completa de hematita, mais solúvel ao ataque DCB, através da espectrofotometria de absorção atômica. A determinação de Fe total foi obtida após tratamento das amostras com $\mathrm{H}_{2} \mathrm{SO}_{4} 1: 1$ (volume).

\section{Testes de adsorção}

A adsorção de fósforo pelos solos foi determinada conforme descrito por Olsen e Watanabe, ${ }^{5}$ empregando-se 24 h de agitação horizontal da suspensão de $2 \mathrm{~g}$ de TFSA (terra fina seca ao ar), corrigida posteriormente para TFSE (terra fina seca em estufa), com $40 \mathrm{~mL}$ de solução de $\mathrm{CaCl}_{2} 0,01 \mathrm{~mol} \mathrm{~L}^{-1}$, contendo diferentes concentrações de fósforo. A proporção de fósforo detectado após centrifugação subtraída da quantidade inicial foi considerada como fração adsorvida. Os dados obtidos foram ajustados à equação linear da isoterma de Langmuir,

$$
C /(x / m)=1 / a b+C / b
$$

em que $C$ é a concentração de $\mathrm{P}$, expressa em $\mu \mathrm{g} \mathrm{L}^{-1}$, na solução de equilíbrio, $x / m$ é a quantidade $(\mu \mathrm{g})$ de $\mathrm{P}$ adsorvido/g de solo, $a$ é uma constante relacionada à energia de retenção de $\mathrm{P}$ e $b$ é a adsorção máxima de P. Foram utilizadas três repetições.

\section{RESULTADOS E DISCUSSÃO}

\section{Caracterização dos solos por espectroscopia Mössbauer: análises a $298 \mathrm{~K}$}

A Figura 1 apresenta os parâmetros Mössbauer das amostras à temperatura do ambiente. O espectro Mössbauer a $298 \mathrm{~K}$ da amostra LVdfg-NC foi ajustado com um modelo independente de distribuição de campo hiperfino, hematita. Observa-se que o campo máximo obtido $\left(B_{h f}(\max )=49,1 \mathrm{~T}\right)$ é bem menor que o valor característico para a hematita, 51,8 T, o que, de acordo com Cornell e Schwertmann, ${ }^{4}$ é mais comumente devido à substituição isomórfica de $\mathrm{Fe}^{3+}$ por $\mathrm{Al}^{3+}$ e ao pequeno tamanho de partícula da hematita. Além de hematita, aparece um dupleto, presumivelmente, devido a $\mathrm{Fe}^{3+}$ paramagnético, como da estrutura de aluminossilicatos, ou a óxidos de ferro sob relaxação superparamagnética, como hematita e/ou goethita com tamanho médio de partículas muito pequeno. Estes resultados estão de acordo com os dados obtidos pela difratometria de raios X da fração argila ferro-concentrada, da amostra de solo correspondente,, 5 em que se observa uma reflexão alargada referente à goethita $(h k l=101)$, sugerindo amostra com pequenos tamanhos de partícula. A amostra correspondente ao solo cultivado (LVdfg-C) apresenta perfil Mössbauer semelhante, a $298 \mathrm{~K}$, indicando hematita como óxido de ferro dominante, com a mesma área relativa $(\sim 70 \%)$ da encontrada para a amostra referente ao solo não cultivado.

Os espectros Mössbauer para as amostras LVdft, dos solos cultivados e não cultivados, são razoavelmente similares aos das amostras LVdfg, com estrutura hiperfina característica de hematita e, como no caso anterior, com $\mathrm{Fe}^{3+}$ em fase oxídica superparamagnética. Para as amostras LVdft observou-se apenas quantidade relativa maior de hematita, quando comparadas às amostras LVdfg. O mesmo padrão espectral foi encontrado para as amostras LVw, tanto para solos cultivados quanto para não cultivados.

No caso das amostras LAd e LAx, para as duas situações, solos cultivado e não cultivado, foram encontradas principalmente fases superparamagnéticas, como sugerido pelo dupleto central, nos espectros. Os parâmetros Mössbauer obtidos dos espectros 298 K são apresentados na Tabela 1.

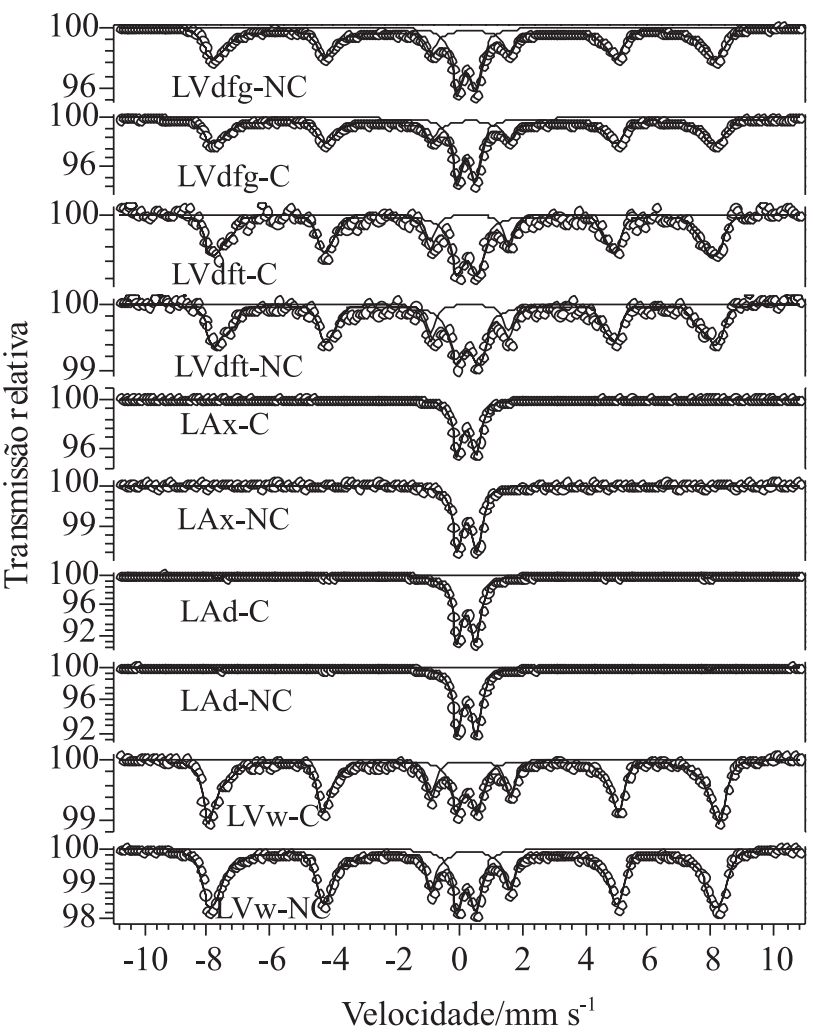

Figura 1. Espectros Mössbauer à temperatura ambiente ( 298 K) das amostras de Latossolos

\section{Caracterização dos solos por espectroscopia Mössbauer: Análises a $110 \mathrm{~K}$}

A fim de se obter melhor uma caracterização das fases mineralógicas presentes, foram realizadas medidas Mössbauer a $110 \mathrm{~K}$ (Figura 2). De maneira geral, os espectros revelam a existência de frações de pequeno tamanho de partícula, que acompanham a substituição isomófica de $\mathrm{Fe}^{3+}$ por $\mathrm{Al}^{3+}$, na estrutura dos óxidos, especificamente, da goethita; a $298 \mathrm{~K}$, apenas hematita foi detectada. Estes resultados estão consistentes com a proporção de 0,18 a $0,33 \mathrm{~mol}^{-1} \mathrm{de} \mathrm{Al}^{3+}$ na estrutura da goethita, ${ }^{6}$ considerada um mineral indicador de ambientes oxidantes, ${ }^{7}$ típicos desses Latossolos.

O espectro para a amostra LVdfg-NC revela padrão de hematita $\left(B_{h f}=52,6 \mathrm{~T}\right)$; $\mathrm{Fe}^{3+}$ paramagnético em coordenação octaédrica e distribuição de campo hiperfino $\left(B_{h f}(\max )=50,2 \mathrm{~T}\right)$, muito provavelmente correspondendo à goethita superparamagnética. Estes resultados sugerem também a ocorrência uma goethita altamente substituída por $\mathrm{Al}^{3+}$, conforme descrito por Cornell e Schwertmann. ${ }^{4}$ Uma maior segurança para estas interpretações requer coleta de dados a temperaturas ainda mais baixas (como nas condições criogênicas sob hélio líquido, 4 K), para bloqueio da relaxação superparamagnética e uma melhor resolução espectral. De maneira geral, as demais amostras seguem esse mesmo 
Tabela 1. Parâmetros Mössbauer obtidos à temperatura ambiente para as amostras de Latossolos brasileiros

\begin{tabular}{|c|c|c|c|c|c|c|}
\hline Amostra & fase & $\delta / \mathrm{mm} \mathrm{s}^{-1}$ & $\varepsilon, \Delta / \mathrm{mm} \mathrm{s}^{-1}$ & $B_{h f} / \mathrm{T}$ & $\Gamma / \mathrm{mm} \mathrm{s}^{-1}$ & $A R / \%$ \\
\hline \multirow{2}{*}{ LVdfg-C } & $\mathrm{Hm}$ & 0,36 & $-0,20$ & 49,2 & 0,31 & 70 \\
\hline & $\mathrm{Fe}^{3+}$ & 0,35 & 0,55 & & 0,40 & 30 \\
\hline \multirow{2}{*}{ LVdfg-NC } & $\mathrm{Hm}$ & 0,36 & $-0,20$ & 49,1 & 0,31 & 71 \\
\hline & $\mathrm{Fe}^{3+}$ & 0,36 & 0,55 & & 0,40 & 29 \\
\hline \multirow{2}{*}{ LVdft-C } & $\mathrm{Hm}$ & 0,36 & $-0,18$ & 50,3 & 0,31 & 66 \\
\hline & $\mathrm{Fe}^{3+}$ & 0,37 & 0,62 & & 0,55 & 34 \\
\hline \multirow{2}{*}{ LVdft-NC } & $\mathrm{Hm}$ & 0,36 & $-0,15$ & 50,3 & 0,31 & 64 \\
\hline & $\mathrm{Fe}^{3+}$ & 0,39 & 0,68 & & 0,60 & 36 \\
\hline LAx-C & $\mathrm{Fe}^{3+}$ & 0,35 & 0,57 & & 0,37 & 100 \\
\hline LAx-NC & $\mathrm{Fe}^{3+}$ & 0,36 & 0,59 & & 0,39 & 100 \\
\hline \multirow{2}{*}{ LAd-C } & $\mathrm{Fe}^{3+}$ & 0,35 & 0,56 & & 0,38 & 91 \\
\hline & $\mathrm{Hm}$ & 0,37 & $-0,22$ & 48,2 & 0,61 & 9 \\
\hline \multirow{2}{*}{ LAd-NC } & $\mathrm{Fe}^{3+}$ & 0,35 & 0,58 & & 0,48 & 88 \\
\hline & $\mathrm{Hm}$ & 0,37 & $-0,20$ & 48,4 & 0,60 & 12 \\
\hline \multirow{2}{*}{ LVw-C } & $\mathrm{Hm}$ & 0,36 & $-0,22$ & 50,6 & 0,31 & 76 \\
\hline & $\mathrm{Fe}^{3+}$ & 0,36 & 0,62 & & 0,48 & 24 \\
\hline \multirow{2}{*}{ LVw-NC } & $\mathrm{Hm}$ & 0,36 & $-0,22$ & 49,7 & 0,31 & 80 \\
\hline & $\mathrm{Fe}^{3+}$ & 0,35 & 0,56 & & 0,43 & 20 \\
\hline
\end{tabular}

$\delta=$ deslocamento isomérico em relação ao $\alpha \mathrm{Fe}, \varepsilon=$ deslocamento quadrupolar, $\Delta=$ desdobramento quadrupolar, Bhf $=$ campo hiperfino, $\Gamma=$ largura de linha à meia altura, $\mathrm{AR}=$ área relativa ao subespectro, $\mathrm{Hm}=$ hematita, $\mathrm{Fe}+3=$ alto spin de coordenação octaédrica.

padrão espectral, ressaltando-se que, para os solos cultivados e não cultivados, LAx e Lad, o efeito do sexteto aparece mais bem definido, indicando que essas amostras apresentam elevado teor de $\mathrm{Al}^{3+}$ substituindo isomorficamente o $\mathrm{Fe}^{3+}$. Além disso, não se observou variação significativa na natureza dos óxidos de ferro, comparando-se os solos cultivados e não cultivados, exceto para o solo com óxidos mais ricos em alumínio, especificamente, amostra LAx, em que a amostra do solo cultivado apresenta maior teor de goethita $(\mathrm{AR}=87 \%)$; para a amostra do solo não cultivado, $\mathrm{AR}=78 \%$ (Tabela 1). Uma possível explicação estaria relacionada ao fato de o cultivo por longos períodos promover a liberação de parte do Fe mais reativo, ligado aos compostos orgânicos, e sua posterior re cristalização, na forma de goethita (nessas condições, mais estável). A taxa IC $=\mathrm{Fe}_{\mathrm{o}} / \mathrm{Fe}_{\mathrm{d}}$ (ferro extraído pelo oxalato de amônio ácido $/$ ferro extraído pelo ditionito-citrato-bicarbonato de sódio ${ }^{9}$ ) é utilizada como um índice de cristalinidade dos óxidos de Fe no solo, estando os valores mais elevados relacionados à presença de inibidores de cristalização, que podem dificultar a transformação do precursor ferridrita $\left(\mathrm{Fe}_{5} \mathrm{HO}_{8} .4 \mathrm{H}_{2} \mathrm{O}\right)$ em óxidos mais bem cristalizados. A ocorrência de valores mais baixos de IC para a amostra do solo cultivado $(0,06)$ e mais elevados para a do solo não cultivado $(0,30)^{7}$ é consistente com esta hipótese. ${ }^{10}$

\section{Testes de adsorção}

A Tabela 3 mostra os resultados do teor de fósforo total $\left(\mathrm{mg} \mathrm{kg}^{-1}\right)$ adsorvido nas amostras dos Latossolos estudados.

Os resultados da Tabela 3 mostram que o teor de fósforo adsorvido tende a diminuir nas amostras dos Latossolos cultivados. Motta et $a l .{ }^{5}$ apresentam três justificativas plausíveis para a tendência observada: redução das cargas elétricas superficiais positivas pela calagem; incremento da taxa de decomposição dos compostos orgânicos, com geração de frações de menor massa molar e/ou de maior solubilidade também pela calagem ${ }^{11}$ e remoção de parte dos elementos em solução $(\mathrm{Ca}, \mathrm{Fe}$ e $\mathrm{Al})$ por precipitação com fósforo, pela adubação fosfatada. ${ }^{12}$

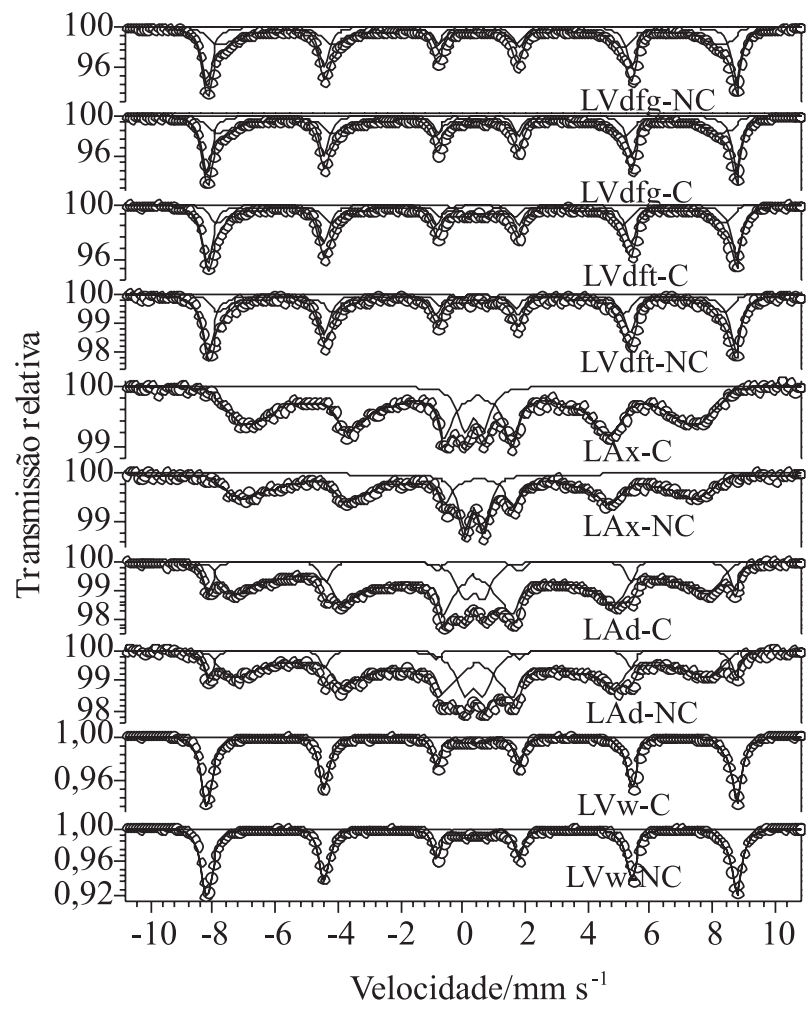

Figura 2. Espectros Mössbauer a $110 \mathrm{~K}$ das amostras de Latossolos

Um resultado diferente do comumente relatado na literatura consiste no fato de que a amostra LVdft, de Latossolo Vermelho distroférrico derivado de tufito, apresenta a maior capacidade de adsorção de fósforo, mesmo com baixas proporções de goethita, na sua constituição mineralógica, de acordo com os dados Mössbauer obtidos a $110 \mathrm{~K}$. Ainda de acordo com os ajustes dos espectros Mös- 
Tabela 2. Parâmetros Mössbauer obtidos a $110 \mathrm{~K}$ das amostras de Latossolos brasileiros

\begin{tabular}{|c|c|c|c|c|c|c|}
\hline Amostra & fase & $\delta / \mathrm{mm} \mathrm{s}^{-1}(0,05)$ & $\varepsilon, \Delta / \mathrm{mm} \mathrm{s}^{-1}(0,05)$ & $B_{h f} / \mathrm{T}$ & $\Gamma / \mathrm{mm} \mathrm{s}^{-1}(0,05)$ & $R A / \%(1)$ \\
\hline \multirow{3}{*}{ LVdfg-C } & $\mathrm{Gt}$ & 0,46 & $-0,24$ & 50,1 & 0,31 & 50 \\
\hline & $\mathrm{Hm}$ & 0,48 & $-0,20$ & 52,6 & 0,36 & 48 \\
\hline & $\mathrm{Fe}^{3+}$ & 0,52 & 0,59 & & 0,50 & 2 \\
\hline \multirow{3}{*}{ LVdfg-NC } & Gt & 0,47 & $-0,24$ & 50,2 & 0,31 & 49 \\
\hline & $\mathrm{Hm}$ & 0,48 & $-0,20$ & 52,6 & 0,38 & 49 \\
\hline & $\mathrm{Fe}^{3+}$ & 0,55 & 0,56 & & 0,40 & 2 \\
\hline \multirow{3}{*}{ LVdft-C } & $\mathrm{Gt}$ & 0,46 & $-0,24$ & 50,4 & 0,31 & 41 \\
\hline & $\mathrm{Hm}$ & 0,48 & $-0,18$ & 52,6 & 0,41 & 53 \\
\hline & $\mathrm{Fe}^{3+}$ & 0,50 & 0,59 & & 0,55 & 6 \\
\hline \multirow{3}{*}{ LVdft-NC } & $\mathrm{Gt}$ & 0,47 & $-0,24$ & 50,1 & 0,31 & 38 \\
\hline & $\mathrm{Hm}$ & 0,47 & $-0,17$ & 52,4 & 0,45 & 59 \\
\hline & $\mathrm{Fe}^{3+}$ & 0,49 & 0,59 & & 0,50 & 3 \\
\hline \multirow{2}{*}{ LAx-C } & Gt & 0,47 & $-0,25$ & 44,5 & 0,31 & 87 \\
\hline & $\mathrm{Fe}^{3+}$ & 0,46 & 0,63 & & 0,50 & 13 \\
\hline \multirow{2}{*}{ LAx-NC } & Gt & 0,46 & $-0,30$ & 45,6 & 0,31 & 78 \\
\hline & $\mathrm{Fe}^{3+}$ & 0,47 & 0,63 & & 0,44 & 22 \\
\hline \multirow{3}{*}{ LAd-C } & $\mathrm{Gt}$ & 0,48 & $-0,25$ & 47,2 & 0,31 & 77 \\
\hline & $\mathrm{Hm}$ & 0,48 & $-0,22$ & 52,3 & 0,38 & 12 \\
\hline & $\mathrm{Fe}^{3+}$ & 0,46 & 0,63 & & 0,60 & 11 \\
\hline \multirow{3}{*}{ LAd-NC } & $\mathrm{Gt}$ & 0,48 & $-0,24$ & 47,5 & 0,31 & 74 \\
\hline & $\mathrm{Hm}$ & 0,49 & $-0,18$ & 52,3 & 0,35 & 11 \\
\hline & $\mathrm{Fe}^{3+}$ & 0,47 & 0,64 & & 0,65 & 15 \\
\hline \multirow{2}{*}{ LVw-C } & $\mathrm{Hm}$ & 0,46 & $-0,20$ & 53,0 & 0,31 & 95 \\
\hline & $\mathrm{Fe}^{3+}$ & 0,47 & 0,63 & & 0,55 & 5 \\
\hline \multirow{2}{*}{ LVw-NC } & $\mathrm{Hm}$ & 0,47 & $-0,20$ & 52,9 & 0,31 & 93 \\
\hline & $\mathrm{Fe}^{3+}$ & 0,48 & 0,63 & & 0,55 & 7 \\
\hline
\end{tabular}

$\delta=$ deslocamento isomérico em relação ao $\alpha \mathrm{Fe}, \varepsilon=$ deslocamento quadrupolar, $\Delta=$ desdobramento quadrupolar, $B_{h f}=$ campo hiperfino, $\Gamma=$ largura de linha à meia altura, $A R=$ área relativa ao subespectro, $\mathrm{Gt}=$ goethita, $\mathrm{Hm}=$ hematita, $\mathrm{Fe}^{+3}=$ alto spin de coordenação octaédrica.

Tabela 3. Teores de fósforo adsorvidos $\left(\mathrm{mg} \mathrm{kg}^{-1}\right)$ nos diferentes Latossolos cultivados (C) e não cultivados (NC)

\begin{tabular}{lcc}
\hline Latossolos & $\mathrm{NC}$ & $\mathrm{C}$ \\
\hline LVdfg & $1393(2)$ & $1393(2)$ \\
LVdft & $3000(2)$ & $2092(2)$ \\
LAx & $476(2)$ & $324(3)$ \\
LAd & $621(2)$ & $676(2)$ \\
LVw & $1233(3)$ & $1052(3)$ \\
\hline
\end{tabular}

sbauer (Tabela 2), a área relativa do sexteto referente à goethita para a amostra do solo não cultivado foi de $38 \%$; para a do solo cultivado foi de $41 \%$, sendo maiores as áreas referentes à hematita com valores de área relativa de 59 e 53\%, para o solo não cultivado e cultivado, respectivamente. A quantidade de fósforo adsorvida pode ser mais claramente correlacionada com o teor total de ferro presente nos Latossolos (Figura 3).

A goethita é considerada ser, de maneira geral, o principal componente da fração argila responsável pela adsorção de fósforo em Latossolos do Brasil. ${ }^{13} \mathrm{~A}$ influência da substituição isomórfica de $\mathrm{Fe}$ por $\mathrm{Al}$ e da área superficial específica da goethita sobre o fenômeno de adsorção de fósforo também tem sido citada na literatura. ${ }^{14}$ Esses dois resultados esperados, maior adsorção pela presença de goethita e pelo aumento de substituição de $\mathrm{Fe}$ por $\mathrm{Al}$, não foram observados nas amostras caracterizadas neste trabalho. Pelos padrões espectrais Mössbauer, as amostras de Latossolos Amarelos (LAx e LAd), que apresentaram apenas dupletos nos espectros à temperatura do am- biente, são as com maior substituição isomórfica, como sugerem os sextetos típicos de óxidos de ferro, apenas nas análises a $110 \mathrm{~K}$. De fato, as análises químicas efetuadas para a determinação de alumínio substituído na goethita dos Latossolos apresentaram valores $28 \mathrm{~g}$ $\mathrm{kg}^{-1}$ para os solos LAx cultivados e não cultivados. O solo LAd não cultivado apresentou teor de alumínio de $0,29 \mathrm{~mol}^{-1} \mathrm{e}$ este, cultivado, teor de $0,28 \mathrm{~mol}^{-1}$. Por outro lado, para a amostra LVw os espectros Mössbauer não apresentam os padrões para os teores de alumínio substituídos. Para esse solo os valores das análises químicas foram de 29 e $30 \mathrm{~g} \mathrm{~kg}^{-1}$ para o solo não cultivado e cultivado, respectivamente. Os solos LVdfg e LVdft apresentam teores de alumínio significativamente menores, comparados aos outros solos, conforme perfis dos espectros Mössbauer. Os teores de alumínio na goethita para todos os solos estudados estão dispostos na Tabela 4.

Assim, a maior substituição isomórfica na goethita, indicada pelos dupletos dos espectros a $298 \mathrm{~K}^{15}$ parece dificultar a adsorção de fósforo, provavelmente devido à diminuição do número de grupos $\mathrm{OH}$ superficiais. Ainda não existem estudos conclusivos sobre o mecanismo de adsorção de espécies de fósforo em óxidos de ferro. Há, no entanto, consenso de que as formas iônicas de fósforo sejam adsorvidas predominantemente como complexos bidentados, em sítio binuclear. A Figura 4 mostra esquematicamente o mecanismo proposto ${ }^{6}$ de adsorção de fósforo em um sítio binuclear, na superfície de um óxido de ferro: a presença de grupos $\mathrm{OH}$ favorece a adsorção específica das espécies iônicas de fósforo, sugerindo que a diminuição de disponibilidade desses grupos, pela substituição de $\mathrm{Fe}$ por $\mathrm{Al}$, provocaria decréscimo da capacidade de adsorção, como observado neste 

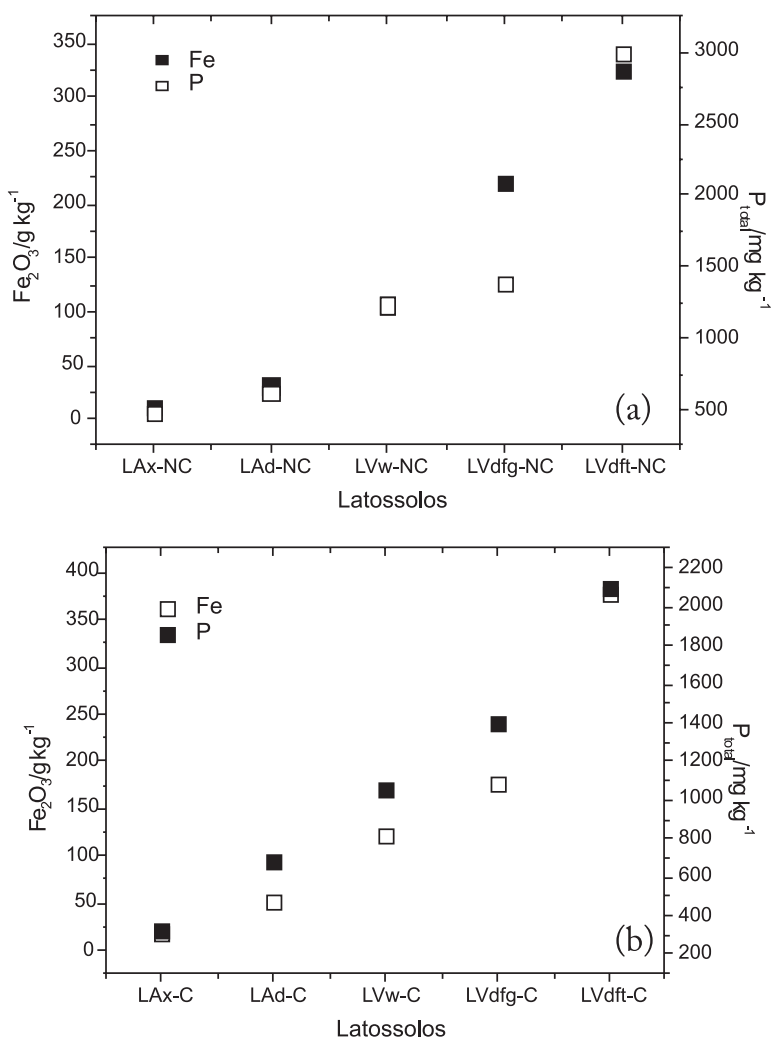

Figura 3. Variação do teor de fósforo adsorvido, em função da quantidade de óxido de ferro total nas amostras de Latossolos, não cultivados (a) e cultivados $(b)$
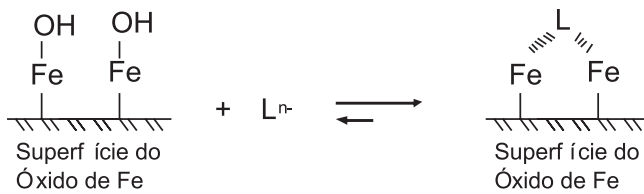

Figura 4. Esquema ilustrando o mecanismo de adsorção específica de espécies de fósforo em sítios bidentados na superfície de óxidos de ferro presentes no solo $(L=$ formas de fósforo dependentes do $\mathrm{pH})$

Tabela 4. Teores de alumínio presentes na goethita $\left(\mathrm{g} \mathrm{kg}^{-1}\right)$ nos diferentes Latossolos cultivados $(\mathrm{C})$ e não-cultivados (NC)

\begin{tabular}{lcc}
\hline Latossolos & NC & C \\
\hline LVdfg & $15(2)$ & $21(2)$ \\
LVdft & $25(2)$ & $19(2)$ \\
LAx & $25(2)$ & $28(2)$ \\
LAd & $23(2)$ & $22(2)$ \\
LVw & $29(2)$ & $30(2)$ \\
\hline
\end{tabular}

trabalho. O modelo está também de acordo com os resultados obtidos por Oliveira et al. ${ }^{15}$ em que goethitas sintéticas dopadas com nióbio apresentaram aumento de sítios vacantes de oxigênio (deficiência no número de coordenação, pela ausência dos grupos oxigenados), na medida em que ocorre a substituição isomórfica.

\section{CONCLUSÕES}

Os dados Mössbauer coletados com as amostras na temperatura do ambiente apresentam padrões espectrais característicos de materiais de pequeno tamanho de partícula, sendo possível a identificação segura apenas de hematita, na maioria dos materiais de solo estudados. No entanto, análises Mössbauer a $110 \mathrm{~K}$ mostram também a ocorrência de goethita superparamagnética, em partículas muito pequenas. Estes resultados são importantes, na indicação de solos também com potencialidade para uso como adsorventes de poluentes. Os Latossolos cultivados tendem a adsorver menor quantidade de fósforo e isso está relacionado às alterações promovidas pela calagem e adubação fosfatada.

\section{AGRADECIMENTOS}

À Fapemig, ao CNPq e à Capes.

\section{REFERÊNCIAS}

1. Day, P. R.; Methods of Soil Analysis, 3rd ed., Madison: ASA, 1965.

2. Kämpf, N.; Schwertmann, U.; Clays Clay Miner. 1982, 30, 401.

3. Torrent, J.; Barron, V.; Schwertmann, U.; Soil Sci. Soc. Am. J. 1990, 54, 1007.

4. Cornell, R.M.; Schwertmann, U.; The Iron Oxides, 3rd ed., WeinheimVHC: New York, 2003

5. Motta, P. E. F.; Curi, N.; Siqueira, J. O.; Van Raij, B.; Neto, A. E. F.; Lima, J. M.; R. Bras. Ci. Solo 2002, 26, 349.

6. Motta, P. E. F.; Tese de Doutorado, Universidade Federal de Lavras, Brasil, 1999.

7. Fitzpatrick, R. W.; Schwertmann, U.; Geoderma 1982, 27, 335.

8. Schwertmann, U.; Z. Pflanzenernahr. und Bodenkd. 1964, 105, 105.

9. Mehra, O. P.; Jackson, M. L.; Clays Clay Minerals Conference, Washington, United States, 1958.

10. Resende, M.; Curi, N.; Ker, J. C.; Rezende, S. B.; Mineralogia de solos brasileiros - interpretação e aplicações, $1^{\text {a }}$ ed., Editora UFLA: Lavras, 2005.

11. Silva, C. A.; Anderson, S. J.; Guilherme, L. R. G.; R. Bras. Ci. Solo 2000, 24, 495

12. Kämpf, N.; Curi, N.; Tópicos Ciência do Solo 2000, 1, 111.

13. Bahia filho, A. F. C.; Braga, J. M.; Resende, M.; Ribeiro, A. C.; R. Bras. Ci. Solo 1983, 7, 221.

14. Resende, M.; Tese de Doutorado, Purdue University, Estados Unidos, 1976.

15. Oliveira, L. C. A.; Gonçalves, M.; Oliveira, D. Q. L.; Guarieiro, A. L. N.; Pereira, M. C.; Quim. Nova 2007, 30, 925. 